\title{
Clinico-Pathogenetic Regularities of Evaluation of the Effectiveness of the Restorative Treatment in Patients After Acute Coronary Syndrome at the Stages of Rehabilitation
}

\author{
Roksolana Nesterak
}

\begin{abstract}
The implementation and improvement of new treatment methods for patients with acute coronary syndrome poses new challenges in finding the newest methods of rehabilitation and restorative treatment. The effectiveness of such interventions depends on the integrated approach and patient's involvement. Accepting the disease, the patient builds an idea about the disease and integrates the internal picture of the disease into a new internal picture of health. The ability to see illness only as part of health is a strategy of self-preservation and self-renewing behaviour.

Objective of the study. To evaluate the clinical-pathogenetic regularities of the effectiveness of the restorative treatment in patients after acute coronary syndrome (ACS) at the stages of rehabilitation.

Materials and methods. There were 135 patients with acute coronary syndrome without ST segment elevation were examined, who were divided into the groups depending on the used treatment tactics - conservative or invasive - PCl. Clinical-anamnestic indices, psychometric, subjective and objective data were analyzed. Along with the traditional treatment, there was used the rehabilitation of patients according to the author's method, based on a multidisciplinary approach with optimization of the internal picture of health. The examinations were performed before the beginning of rehabilitation, after 1 week, 1 month and 6 months.

Results. The use of the program, along with the traditional treatment of patients, helped to improve the effectiveness of treatment by normalization of the major objective indices, reduction of the anxiety levels, and improvement of life quality. More pronounced dynamics was noted in patients with acute coronary syndrome without ST segment elevation with invasive treatment tactics.

Conclusions. Clinical-psychological rehabilitation of patients with acute coronary syndrome without ST-segment elevation can improve the effectiveness of rehabilitation and rehabilitation, regardless of treatment tactics, although the effect is somewhat higher in patients with invasive therapy tactics. This approach helps to improve the course of the disease. A multidisciplinary approach involving a cardiologist and a physical restorative and rehabilitation physician, a psychologist and a physiotherapist is important.
\end{abstract}

\section{Keywords}

acute coronary syndrome; anxiety; treatment; rehabilitation.

Ivano-Frankivsk National Medical University, Ivano-Frankivsk, Ukraine

Corresponding author: roxolana.nesterak@gmail.com 


\section{Clinico-Pathogenetic Regularities of Evaluation of the Effectiveness of the Restorative Treatment in Patients After Acute Coronary Syndrome at the Stages of Rehabilitation - 2/8}

\section{Problem statement and analysis of the latest research}

Cardiovascular disease (CVD) is an important problem of nowadays, leading to socio-economic losses at the expense of significant costs for both rehabilitation and treatment [1]. Today the methods of diagnosis and treatment of CVD are being improved, that's why there is a problem in finding new opportunities for the restoration of patients, their return to a full-fledged social life, with an individual approach depending on the tactics of diagnosis and treatment.

Cardiorehabilitation - is a coordinated set of measures needed to positively influence the underlying causes of CVD, as well as to provide the best physical, mental and social conditions that allow patients to retain or restore optimal functioning in society and change their lifestyle to slow down or promote illness regression (as defined by the British Association of Preventive Cardiology and Rehabilitation) [2].

The rehabilitation is planned individually for each patient, including his medical, physical, psychological, social, family and professional necessities.

Each stage involves an individual and differentiated approach, taking into account the severity of the condition, the functional reserves of the circulatory system, the stage and complications of the underlying disease, the presence of concomitant pathology, the course of the postoperative period. Efficiency control should be performed at each stage [3].

One of the components of the rehabilitation effectiveness improvement is the clinical-psychological approach with the use of the "Program of clinical-psychological rehabilitation of cardiologic patients by optimization of the internal picture of health" [4].

The objective of the study. To evaluate the clinical-pathogenetic regularities of the effectiveness of rehabilitation in patients after acute coronary syndrome (ACS) at the stages of rehabilitation.

\section{Materials and Methods}

There were examined 135 patients with acute coronary syndrome (ACS) without ST segment elevation. The examined subjects were distributed according to the treatment tactics (conservative or invasive PCI). The variation of sample according to the age and gender corresponded to the population (Fig. 1), of them women were: under 45 years old - none; 45-59 years - conservative treatment $8.33 \%$, PCI - 5.33\%; 60-74 years were used conservative therapy $-21.67 \%, \mathrm{PCI}-17.33 \%$; 75 years or more were used conservative treatment $-16.67 \%$, percutaneous coronary intervention PCI $-8.00 \%$.

Distribution of examined subjects according to age

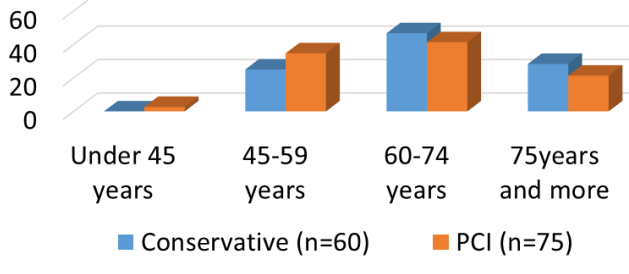

Figure 1. Distribution of the sample according to the age and gender.

Examination of patients was performed depending on the form of CHD and the method of revascularization. All patients received standard therapy for patients with $\mathrm{CHD}$, depending on the form of $\mathrm{CHD}$ and in accordance with the recommendations of the Working Groups of the European and Ukrainian Societies of Cardiologists.

Rehabilitation of patients with ACS without ST segment elevation was performed according to the author's "Program of clinical-psychological rehabilitation of cardiological patients by optimization of the internal picture of health" [5]. The complex of diagnostic methods was implemented at the key stages of rehabilitation: before the beginning of rehabilitation, after 1 week, 1 month and 6 months. Diagnostic methods: "Scale for assessment of the level of reactive (situational) and personal anxiety" of Spielberg-Hanin; SF-36 - a short form of non-specific questionnaire for determination of the life quality (The 36-Item Short Form 


\section{Clinico-Pathogenetic Regularities of Evaluation of the Effectiveness of the Restorative Treatment in Patients After Acute Coronary Syndrome at the Stages of Rehabilitation - 3/8}

Health Survey); additional: conversation, observation; adequate methods of statistical processing of the received information were applied.

Statistical processing was performed using software "Microsoft Excel" and "Statistica" v. 10.0 StatSoft, USA. The results were subjected to statistical processing by the methods of variational statistics (arithmetic mean, standard error, standard deviation, confidence interval). The possibility of differences between the comparison groups was determined using Student's parametric criterion. Statistical testing of hypotheses to determine differences between nonparametric features was performed using the $\chi^{2}$-criterion and z-criterion. Results with $\mathrm{p}<0.05$ were considered statistically significant.

\section{Results and Discussion}

Analyzing the dynamics of objective indices in patients with ACS without ST-segment elevation with conservative treatment tactics, the gradual decrease of angina attacks in more than half of patients during the month of rehabilitation was observed. After 6 months of treatment, angina attacks were noted by one-third of patients in traditional rehabilitation and $5 \%$ in the "Program" use. Dynamics of dyspnea changes during physical activity occurred according to the same pattern (Table 1).

It was also found that at the beginning of treatment, the same number of patients of these groups indicated fast fatigability and general weakness, and after 6 months of rehabilitation according to the "Program", the percentage of such patients was the lowest. In the course of rehabilitation, there is a gradual decrease in the symptoms of edema and cyanosis in all groups of patients.

Quality of life is a characteristic, based on the subjective perception of physical, psychological, emotional and social functioning. We have proved that the study of peculiarities of life quality of a cardiac patient is an effective marker of evaluation of the quality and effectiveness of cardiorehabilitation [6]. Diagnosis of patients with ACS, without ST segment elevation at the initial stage of rehabilitation showed not high values of quality of life according to all scales; a dependence of life quality on the chosen treatment tactics (invasive or conservative) was revealed (Fig. 2).

According to most scales, the quality of life is higher in patients who have received invasive treatment tactics, because of dramatic changes in the patient's clinical condition. Age, individualpsychological and gender differences are the major reasons for the decrease of patient's quality of life. Social factors and attitude toward the disease are equally important. The physical component of life quality is influenced by: the speed of providing assistance, comorbidity, age peculiarities; the psychological component is influenced by: the attitude to the disease, its duration, anxiety, depression, etc. [6].

An evaluation of the effectiveness of rehabilitation showed a positive change in each of the scales in patients who underwent rehabilitation according to the "Program".

Analyzing the differences according to the indices, we've note a particularly significant difference according to the scale of "Mental Health", both in the group with the conservative tactics and in the group with invasive tactics of treatment, which testifies to the overall optimization of IPH. There is practically no difference in the strategies of rehabilitation according to the scale "Social functioning", although there is a significant difference with the initial indices. We can say that the improvement of physical condition, attention to health allows the patient to be more socially active. The tendency of higher scores according to all the scales in the group with invasive treatment tactics, who underwent the rehabilitation according to the "Program", persists (Fig. 3).

The differentiation of the identified factors leads to the use of new approaches to cardiorehabilitation, in particular to the use of multidisciplinary approach to provide medical, physical and psychological parts of it for the purpose of complete correction of the physical, psychological, emotional and social functioning of the patient. These requirements are met by the "Program".

The internal picture of health, as a subjective reflection on the individual's state of the person's health, largely determines the psychosomatic po- 


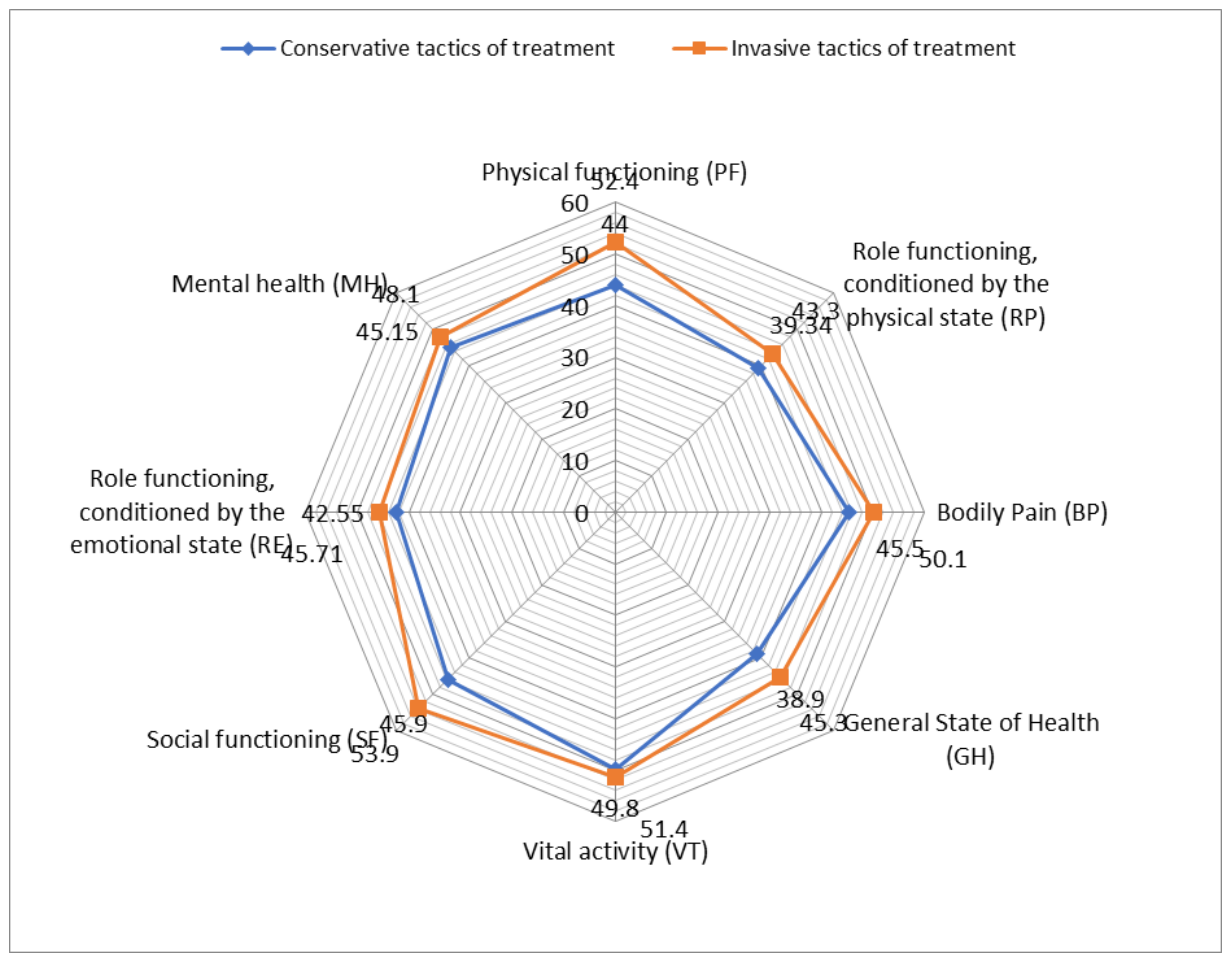

Figure 2. Quality of life of patients with ACS, without elevation of the ST segment when admitted to the Rehabilitation Department.

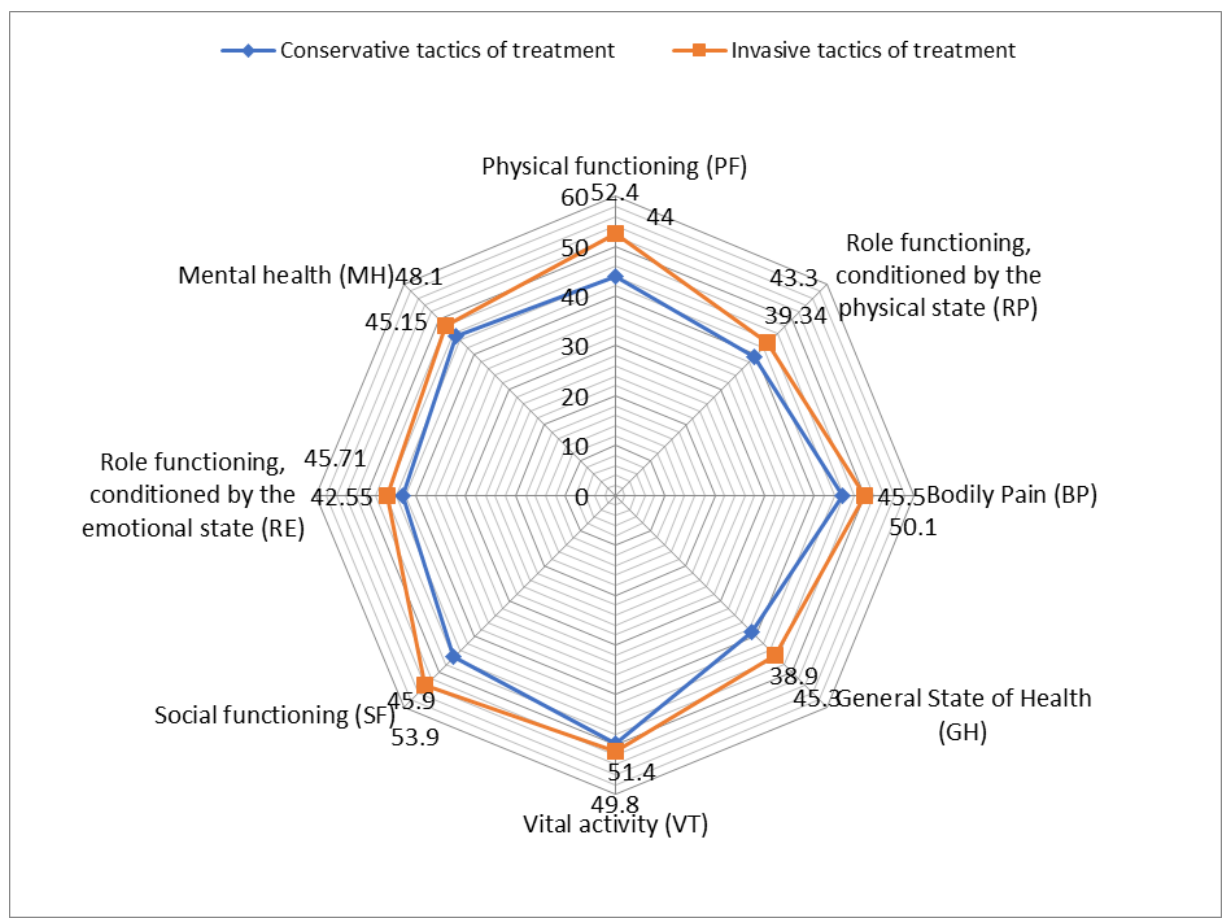

Figure 3. Comparative Diagram of Life Quality of Patients with Invasive Treatment Tactics. 


\section{Clinico-Pathogenetic Regularities of Evaluation of the Effectiveness of the Restorative Treatment in Patients After Acute Coronary Syndrome at the Stages of Rehabilitation - 5/8}

Table 1. Dynamics of main complaints and data of objective examination in patients with ACS without elevation of the ST segment, who were provided conservative treatment tactics.

\begin{tabular}{|c|c|c|c|c|c|c|}
\hline \multirow{2}{*}{ Index } & \multicolumn{3}{|c|}{ Traditional treatment $(\mathrm{n}=20)$} & \multicolumn{3}{|c|}{ Traditional treatment and "Program" $(\mathrm{n}=20)$} \\
\hline & $\begin{array}{c}\text { At the } \\
\text { beginning of } \\
\text { treatment }\end{array}$ & 1 month & 6 months & $\begin{array}{c}\text { At the } \\
\text { beginning of } \\
\text { treatment }\end{array}$ & 1 month & 6 months \\
\hline Attacks & & & & & & \\
\hline $\begin{array}{l}\text { of angina } \\
\text { pectoris }\end{array}$ & $17(85.0 \%)$ & $5(25.0 \%)$ & $5(25.0 \%)$ & $16(80.0 \%)$ & $3(15.0 \%)$ & $1(5.0 \%)$ \\
\hline Dyspnea & $15(75.0 \%)$ & $5(25.0 \%)$ & $5(25.0 \%)$ & $15(75.0 \%)$ & $4(20.0 \%)$ & $2(10.0 \%)$ \\
\hline Interruptions & & & & & & \\
\hline $\begin{array}{l}\text { in the work } \\
\text { of the heart }\end{array}$ & $8(40.0 \%)$ & $4(20.0 \%)$ & $3(15.0 \%)$ & $9(45.0 \%)$ & $2(10.0 \%)$ & $1(5.0 \%)$ \\
\hline Palpitation & $7(35.0 \%)$ & $4(20.0 \%)$ & $4(20.0 \%)$ & $8(40.0 \%)$ & $2(10.0 \%)$ & - \\
\hline $\begin{array}{l}\text { Fast fatigabil- } \\
\text { ity }\end{array}$ & $9(45.0 \%)$ & $6(30.0 \%)$ & $3(15.0 \%)$ & $10(50.0 \%)$ & $7(35.0 \%)$ & $3(15.0 \%)$ \\
\hline $\begin{array}{l}\text { General } \\
\text { weakness }\end{array}$ & $11(55.0 \%)$ & $5(25.0 \%)$ & $4(20.0 \%)$ & $12(60.0 \%)$ & $5(25.0 \%)$ & $2(10.0 \%)$ \\
\hline $\begin{array}{l}\text { Edema of the } \\
\text { lower legs }\end{array}$ & $12(60.0 \%)$ & $9(45.0 \%)$ & $6(30.0 \%)$ & $12(60.0 \%)$ & $7(35.0 \%)$ & $4(20.0 \%)$ \\
\hline Pale skin & $7(35.0 \%)$ & $3(15.0 \%)$ & $3(15.0 \%)$ & $7(35.0 \%)$ & $3(15.0 \%)$ & $2(10.0 \%)$ \\
\hline $\begin{array}{l}\text { Peripheral } \\
\text { cyanosis }\end{array}$ & $4(20.0 \%)$ & - & $1(5.0 \%)$ & $5(25.0 \%)$ & - & - \\
\hline
\end{tabular}

tential of the individual. Accepting the disease, his/her new state, the patient builds an idea of the disease and its real limitations and integrates the internal picture of the disease into a new internal picture of health. The ability to see illness only as a part of health, is a strategy of self-preservation and self-renewing behavior. The internal picture of the patient's health is considered as a special subjective attitude to the person's health, which is expressed in the awareness of its value and activepositive desire for its recovery and improvement in the situation of illness [3]. The formation of IPH is associated with the projection of the objective reality of health on the human consciousness, with the subjective perception and experience of his/her health/illness [5].

Reduction of the negative impact of illness on the human life is possible through the correction of intellectual perceptions of current health state and future prospects of recovery, a set of measures to control emotional experience and feelings about the symptoms of the disease, as well as to build a system of behavior of preservation and restoration of health. Table 3 represents the contents of optimization of each component of the cardiac patient's internal health picture according to the "Program".

\section{Conclusions}

Taking into account the clinical-pathogenetic peculiarities of acute coronary syndrome course is an important component of comprehensive rehabilitation at all its stages. The use of new approaches, in particular clinical-psychological rehabilitation of cardiologic patients, suggests that through the optimization of the components of the patient's IPH, there is an opportunity to improve the quality and effectiveness of their restorative treatment and rehabilitation. It is important to involve an interdisciplinary team of physician-cardiologist and physician of physical and rehabilitation medicine, psychologist. 


\section{Clinico-Pathogenetic Regularities of Evaluation of the Effectiveness of the Restorative Treatment in Patients After Acute Coronary Syndrome at the Stages of Rehabilitation - 6/8}

Table 2. Dynamics of main complaints and data of objective examination in patients with ACS without elevation of the ST segment, who were provided an invasive treatment tactics.

\begin{tabular}{|c|c|c|c|c|c|c|}
\hline \multirow{2}{*}{ Index } & \multicolumn{3}{|c|}{ Traditional treatment $(\mathrm{n}=25)$} & \multicolumn{3}{|c|}{ Traditional treatment with the "Program" $(n=25)$} \\
\hline & $\begin{array}{l}\text { At the } \\
\text { beginning } \\
\text { of } \\
\text { treatment }\end{array}$ & 1 month & 6 months & $\begin{array}{l}\text { At the } \\
\text { beginning } \\
\text { of } \\
\text { treatment }\end{array}$ & 1 month & 6 months \\
\hline $\begin{array}{l}\text { Attacks of } \\
\text { angina pec- } \\
\text { toris }\end{array}$ & $20(80.0 \%)$ & $2(8.0 \%)$ & $1(4.0 \%)$ & $20(80.0 \%)$ & $1(4.0 \%)$ & $1(4.0 \%)$ \\
\hline Dyspnea & $13(52.0 \%)$ & $3(12.0 \%)$ & $3(12.0 \%)$ & $13(52.0 \%)$ & - & - \\
\hline $\begin{array}{l}\text { Interruptions } \\
\text { in the work } \\
\text { of the heart }\end{array}$ & $8(32.0 \%)$ & $2(8.0 \%)$ & $2(8.0 \%)$ & $7(28.0 \%)$ & - & $1(4.0 \%)$ \\
\hline Palpitation & $6(24.0 \%)$ & $3(12.0 \%)$ & $3(12.0 \%)$ & $6(24.0 \%)$ & - & - \\
\hline $\begin{array}{l}\text { Fast fatiga- } \\
\text { bility }\end{array}$ & $9(36.0 \%)$ & $4(16.0 \%)$ & $4(16.0 \%)$ & $9(36.0 \%)$ & $2(8.0 \%)$ & $1(4.0 \%)$ \\
\hline $\begin{array}{l}\text { General } \\
\text { weakness }\end{array}$ & $14(56.0 \%)$ & $4(16.0 \%)$ & $4(16.0 \%)$ & $13(52.0 \%)$ & - & - \\
\hline $\begin{array}{l}\text { Edema of } \\
\text { the lower } \\
\text { legs }\end{array}$ & $11(44.0 \%)$ & $3(12.0 \%)$ & $3(12.0 \%)$ & $10(40.0 \%)$ & $2(8.0 \%)$ & $1(4.0 \%)$ \\
\hline Pale skin & $6(24.0 \%)$ & $4(16.0 \%)$ & $2(8.0 \%)$ & $7(28.0 \%)$ & $3(12.0 \%)$ & $1(4.0 \%)$ \\
\hline $\begin{array}{l}\text { Peripheral } \\
\text { cyanosis }\end{array}$ & $2(8.0 \%)$ & - & - & & - & - \\
\hline
\end{tabular}

The application of the "Program of clinicalpsychological rehabilitation of cardiologic patients by optimization of the internal health picture" facilitates the improvement of the main clinical indicators, decreases anxiety levels and improves the quality of life of patients with acute coronary syndrome (ACS), regardless of the treatment tactics, although the indices are somewhat higher in patients with invasive treatment tactics.

\section{Prospects of Further Researches}

To evaluate the peculiarities of the course and effectiveness of rehabilitation measures in patients after surgical interventions using the clinical-psychological approach.

\section{References}

[1] Kovalenko VM. Problems of health and life expectancy in modern conditions. Kyiv. 2017; 297.

[2] Anderson L, Sharp GA, Norton RJ. et al. Home-based versus centre-based cardiac rehabilitation. Cochrane Database Syst. Rev. 2017; 6:7130. DOI: https://doi.org/ $10.1002 / 14651858$. CD 007130 .pub 4 [PMCid:PMC6481471]

[3] Sledzevska IK, Shumakov VO, Babiy LM, et al. Medical rehabilitation of patients after acute coronary circulation disorders. Kyiv. 2004.

[4] Nesterak RV, Hasiuk MB, Vakaliuk IP. Copyright for the work "Program of clinicalpsychological rehabilitation of cardiologic pa- 


\section{Clinico-Pathogenetic Regularities of Evaluation of the Effectiveness of the Restorative Treatment in Patients After Acute Coronary Syndrome at the Stages of Rehabilitation - 7/8}

tients by optimization of the internal health picture" \# 75681, registered on 29.122017.

[5] Nesterak RV, Hasiuk MB. Quality of life of the patients with acute coronary syndrome without segment elevation. Molody vcheny. 2018; 5(1): 9-13.

[6] Lozhkin HV, Noskov VI, Tolkunova IV. Psychology of human health. 2003; Sevastopol: Weber; 257.

[7] Smirnov VM, Reznikova TN. Basic principles and methods of psychological study of the internal picture of the disease. Methods of psychological diagnosis and correction in the clinic. Meditsina; 1983; 38-62.

[8] Tsvetkova IV. The problem of psychological study of the internal picture of health. Psychological study of processes and the sphere of experiencing by the subject himself as a healthy person. 2012; 1 (21): 11.

[9] Beatty A, Li S, Thomas L, et al. Trends in Referral to Cardiac Rehabilitation After Myocardial Infarction. Data from the National Cardiovascular Data Registry 2007 to 2012. J. Am. Coll. Cardiol. 2014; 63 (23): 2582-2583. DOI: https://doi.org/10.1016/j. jacc.2014.03.030 [PMid:24768872 PMCid:PMC4148417]

[10] Leon AS, Franklin B, Costa F, et al. Cardiac rehabilitation and secondary prevention of coronary heart disease: an American Heart Association scientific statement from the Council on Clinical Cardiology (Subcommittee on Exercise, Cardiac Rehabilitation, and Prevention) and the Council on $\mathrm{Nu}-$ trition, Physical Activity, and Metabolism (Subcommittee on Physical Activity), in collaboration with the American association of Cardiovascular and Pulmonary Rehabilitation. Circulation. 2005; 111(3):369-376. DOI: https://doi.org/10.1161/ 01 . CIR.0000151788.08740.5C

[PMid:15668354]
[11] Nesterak RV, Gasyuk MB. Pilot investigation of the method of interactive training of patients at the stage of medical rehabilitation and treatment. Deutscher Wissenschaftsherold,German Science Herald. 2017;4:38 - 41.

[12] Thompson PD, Buchner D, Pina IL, et al. Exercise and physical activity in the prevention and treatment of atherosclerotic cardiovascular disease: a statement from the Council on Clinical Cardiology (Subcommittee on Exercise, Rehabilitation, and Prevention) and the Council on Nutrition, Physical Activity, and Metabolism (Subcommittee on Physical Activity). J Circulation. 2003; 107(24):3109-3116. DOI: https://doi.org/10.1161/ 01. CIR.0000075572.40158.77

[PMid:12821592]

Received: $2019-12-10$

Revised: $2019-12-17$

Accepted: 2019-12-17 


\section{Clinico-Pathogenetic Regularities of Evaluation of the Effectiveness of the Restorative Treatment in Patients After Acute Coronary Syndrome at the Stages of Rehabilitation - 8/8}

Table 3. Optimization of components of IPH.

\begin{tabular}{|c|c|}
\hline $\begin{array}{l}\text { Components of IPH, } \\
\text { which the "Program" } \\
\text { optimizes }\end{array}$ & Correction content \\
\hline Sensitive component & $\begin{array}{l}\text { - acceptance and understanding of the meaning of physical comfort or discomfort; } \\
\text { - the ability to obtain information about the disease through a symptom; } \\
\text { - expanding the abilities to control the body; } \\
\text { - formation of the actual and resourcefulness of a person. understanding the dynamics } \\
\text { of the disease; } \\
\text { - through the sensation of building an understanding of the prospects of recovery } \\
\text { and the possibilities of the body in the present; } \\
\text { - acceptance of the optimum of physical abilities that can be achieved after treatment } \\
\text { and rehabilitation; } \\
\text { - pleasure of movement and progress in physiotherapy. }\end{array}$ \\
\hline $\begin{array}{l}\text { Value-motivational } \\
\text { component }\end{array}$ & $\begin{array}{l}\text { - increase in motivation of treatment and healthy lifestyle following; } \\
\text { - development of responsibility for his/her health and awareness of his/her own } \\
\text { importance for making vital decisions; } \\
\text { - improvement of the understanding of his/her own system of values and health; } \\
\text { - expansion of life prospects, finding new life goals; } \\
\text { - acceptance of the value of movement, support, restoration, increase of physical } \\
\text { indicators of an organism }\end{array}$ \\
\hline Cognitive component & $\begin{array}{l}\text { - improvement of the range of knowledge on the ways to support and improve health; } \\
\text { - deepening of knowledge about the peculiarities of the disease; } \\
\text { - improvement of self-knowledge, awareness and comprehension of vital decisions } \\
\text { influencing health; } \\
\text { - expansion of resources, development of ability to allocate successful strategies for } \\
\text { improvement of health; } \\
\text { - expansion of the scope of knowledge about the content and effectiveness of physical } \\
\text { activity in physiotherapy }\end{array}$ \\
\hline Emotional component & $\begin{array}{l}\text { - development of emotional self-awareness, improvement of the ability to analyze } \\
\text { his/her mood; } \\
\text { - improvement of self-understanding and self-knowledge; } \\
\text { - facilitating the mastering of skills to overcome the destructive effects of emotions } \\
\text { on health; } \\
\text { - reduction of anxiety level, improvement of well-being; } \\
\text { - formation of successful strategies for the development of confidence and optimiza- } \\
\text { tion of emotional response to his/her health; } \\
\text { - development of awareness of positive emotions from movement. }\end{array}$ \\
\hline Behavioral component & $\begin{array}{l}\text { - focusing on a healthy lifestyle, seeking and understanding the behavior that pro- } \\
\text { motes health; } \\
\text { - development of an understanding of the consequences of his/her own behavior for } \\
\text { health, formation of a setting about the importance of personality for the preservation } \\
\text { of health; } \\
\text { - increase of vital activity and expansion of spheres of activity; } \\
\text { - awareness of strong qualities, disclosure of internal resources, activity according to } \\
\text { new strategies for solving the difficult life situations; } \\
\text { - performance of medical appointments, and physiotherapeutic rehabilitation exer- } \\
\text { cises both under the supervision of a specialist and independently. }\end{array}$ \\
\hline
\end{tabular}

